\title{
Insulin resistance: from bit player to centre stage
}

\author{
Gerald M. Reaven MD
}

Competing interests: Gerald Reaven is a consultant for Genentech.

This commentary was commissioned from Dr. Reaven, a pioneer in the subject of insulin resistance and its role in disease. It has been peer reviewed.

\section{Correspondence to:} Dr. Gerald. M. Reaven, greaven@stanford.edu.

CMAJ 2011. DOI:10.1503 /cmaj.101430
A bout 70 years ago, Himsworth and Kerr published evidence based on the results from modified oral glucose tolerance tests that the ability of insulin to stimulate glucose uptake varied from person to person and that there were at least two forms of diabetes: ${ }^{1}$ insulin sensitive and insulin insensitive. The notion that resistance to insulin action played a role in human disease lay dormant for about 35 years. In the late 1960 s, unaware of the early pioneering publications of Himsworth and Kerr, our research group entertained the possibility that resistance to insulin-mediated glucose uptake was a reasonably common event and played an important role in a number of clinical syndromes. Consequently, we developed a method to directly quantify the ability of insulin to stimulate glucose uptake. Using this experimental approach, we published evidence that insulin action was markedly reduced in patients with type 2 diabetes. ${ }^{2}$

Studies published over the next 10 years (and most recently summarized in 2005) ${ }^{3}$ showed that the overwhelming majority of patients with type 2 diabetes were insulin resistant, that nondiabetic first-degree relatives of patients with type 2 diabetes were insulin resistant and that insulin resistance predicted the development of type 2 diabetes. This article looks at the effect of insulin resistance on several body tissues.

Not only were Himsworth and Kerr correct about the link between insulin resistance and diabetes, it is now apparent that type 2 diabetes is only one of the many clinical syndromes in which insulin resistance plays a major role. Some of the evidence linking insulin resistance to the pathogen-

esis and clinical course of essential hypertension, coronary artery disease, polycystic ovarian syndrome, nonalcoholic liver disease, certain forms of cancer and obstructive sleep apnea was recently summarized in a position paper from the American College of Endocrinology. ${ }^{4}$ Information continues to accumulate concerning these and other clinical syndromes associated with insulin resistance. Less often appreciated, however, is that differences in tissue response to ambient insulin concentrations represent the link between insulin resistance, metabolic abnormalities and clinical syndromes.

Most of the adverse events attributed to insulin resistance are secondary to the effects of compensatory hyperinsulinemia (an attempt at preventing the decompensation of glucose homeostasis) on tissues that either retain normal insulin sensitivity or are hypersensitive to insulin action.

Muscle tissue is the main consumer of glucose. As such, it may not be overstating the case to claim that the so-called trouble begins there. Insulin-mediated glucose uptake by muscle can vary by as much as six-fold in apparently healthy people. ${ }^{5}$ The more resistant the muscle tissue is to insulin, the greater the demand on the pancreatic $b$ cells to maintain the degree of compensatory hyperinsulinemia required to prevent the development of type 2 diabetes. Most people with insulin-resistant muscle tissue do not acquire type 2 diabetes. Instead, they remain insulin resistant or hyperinsulinemic with normal, or near normal, glucose tolerance. ${ }^{3}$

People with a defect in insulin-mediated glucose uptake in muscle also experience less insulin inhibition of adipose-tissue lipolysis. ${ }^{6}$ Although the dose-response curves of insulin action on muscle and adipose tissue are quite different, the degree of insulin resistance in the two types of tissue is highly correlated. Insulin resistance in muscle and adipose tissue results in increases in plasma insulin and free fatty acid concentrations. These changes act on the liver to increase triglyceride synthesis and secretion, thereby initiating a series of metabolic events that result in a highly atherogenic lipoprotein profile: high triglyceride levels and low levels of high-density lipoprotein cholesterol; small, dense, low-density lipoprotein particles; and accumulation of postprandial remnant lipoproteins. These changes are

All editorial matter in CMAJ represents the opinions of the authors and not necessarily those of the Canadian Medical Association. 
each known to contribute to an increased risk of coronary artery disease. ${ }^{7}$

Despite insulin resistance in muscle and adipose tissue, certain tissues, such as the kidneys, retain normal insulin sensitivity. ${ }^{8}$ Compensatory hyperinsulinemia, secondary to insulin resistance in muscle, acts on the kidney to retain salt and water. This may explain why insulin resistance and compensatory hyperinsulinemia predict the development of essential hypertension. Normotensive first-degree relatives of patients with essential hypertension and about $50 \%$ of patients with essential hypertension have been found to have insulin-resistant muscle tissue. ${ }^{9}$ In addition, compensatory hyperinsulinemia decreases uric acid clearance by the kidneys, which leads to increases in the uric acid concentration of plasma. ${ }^{8}$ The sympathetic nervous system also retains normal insulin sensitivity. ${ }^{10}$ Compensatory hyperinsulinemia increases sympathetic nervous system activity. That, in conjunction with sodium retention, contributes to the association between insulin resistance and essential hypertension. ${ }^{9}$ Finally, chronic elevation of plasma insulin concentration, either directly or by interacting with insulin growth factor-1, may contribute to the increased prevalence of certain cancers observed in patients with insulin resistance and hyperinsulinemia. ${ }^{4}$

Some tissues show hypersensitivity to insulin. In the ovaries, insulin stimulates testosterone secretion. Elevated plasma testosterone concentrations in most women with polycystic ovarian syndrome are associated with obesity, resistance to insulin-mediated glucose uptake by muscle and compensatory hyperinsulinemia. ${ }^{11}$

A simple conclusion is that hyperinsulinemia is responsible for the elevated plasma testosterone concentrations seen in polycystic ovarian syndrome. However, a minority of patients with polycystic ovarian syndrome have elevated plasma testosterone concentrations without any defect in insulin action on muscle and show no signs of hyperinsulinemia. This apparent paradox was addressed in a recent study. ${ }^{11}$ Insulinmediated glucose uptake and plasma insulin and testosterone concentrations were determined in weight-matched women with either polycystic ovarian syndrome or normal ovulation, who were further categorized into insulin-resistant or insulin-sensitive subgroups based on a determination of insulin-mediated glucose uptake by muscle. Plasma testosterone concentrations were significantly higher in both groups of women with polycystic ovarian syndrome, but highest in the insulin-resistant subgroup. Although the subgroup of insulin-resistant women with normal ovulation was more insulin resistant and hyper- insulinemic than the subgroup of insulinsensitive women with polycystic ovarian syndrome, the testosterone concentrations of its members were significantly lower. The testosterone levels were even lower in the insulinsensitive women with normal ovulation. These data show that plasma insulin concentrations that are not high enough to increase plasma testosterone concentrations to pathological levels in women who ovulate normally will do so in women with polycystic ovarian syndrome; also, as insulin levels increase, so too does the degree of hyperandrogenism. These results suggest that women with polycystic ovarian syndrome have ovaries that are hypersensitive to insulin stimulation of testosterone production.

In conclusion, insulin plays a major regulatory role in multiple tissues. Various tissues within the same person can be resistant, sensitive or hypersensitive to insulin action. The interplay between the responses to insulin and ambient insulin concentrations contributes to the pathogenesis and clinical course of an increasing number of important syndromes. Given the adverse effect of obesity and decreased physical activity on insulinmediated glucose uptake, ${ }^{12}$ the roles of insulin resistance and compensatory hyperinsulinemia in human disease can only continue to expand.

\section{References}

1. Himsworth HP, Kerr RB. Insulin-sensitive and insulininsensitive types of diabetes mellitus. Clin Sci 1939;4:119-52.

2. Ginsberg H, Kimmerling G, Olefsky JM, et al. Demonstration of insulin resistance in untreated adult onset diabetic subjects with fasting hyperglycemia. J Clin Invest 1975;55:454-61.

3. Reaven GM. Why syndrome X? From Harold Himsworth to the insulin resistance syndrome. Cell Metab 2005;1:9-14.

4. Einhorn D, Reaven GM, Cobin RH, et al. American College of Endocrinology position statement on the insulin resistant syndrome. Endocr Pract 2003;9:237-52.

5. Yeni-Komshian H, Carantoni M, Abbasi F, et al. Relationship between several surrogate estimates of insulin resistance and quantification of insulin-mediated glucose disposal in 490 healthy, nondiabetic volunteers. Diabetes Care 2000;23:171-5.

6. Pei D, Chen Y-D, Hollenbeck CB, et al. Relationship between insulin-mediated glucose disposal by muscle and adipose tissue lipolysis in healthy volunteers. J Clin Endocrinol Metab 1995; 80:3368-72

7. Reaven GM. Compensatory hyperinsulinemia and the development of an atherogenic lipoprotein profile: the price paid to maintain glucose homeostasis in insulin-resistant individuals. Endocrinol Metab Clin North Am 2005;34:49-62.

8. Reaven GM. The kidney: an unwilling accomplice in syndrome X. Am J Kidney Dis 1997;30:928-31.

9. Reaven GM. The role of insulin resistance and compensatory hyperinsulinemia in patients with essential hypertension. In: Oparil S, Weber MW, editors. Hypertension. 2nd ed. Philadelphia (PA): Elsevier; 2005. p. 123-31.

10. Reaven GM, Lithell H, Landsberg L. Hypertension and associated metabolic abnormalities - the role of insulin resistance and the sympathoadrenal system. N Engl J Med 1996;334:374-81.

11. Asagami T, Holmes TH, Reaven G. Differential effects of insulin sensitivity in obese women with polycystic ovary syndrome or normal ovulation. Metabolism 2008;57:1355-60.

12. Bogardus C, Lillioja S, Mott DM, et al. Relationship between degree of obesity and in vivo insulin action in man. Am J Physiol 1985;248(3 Pt 1):E286-91.

Affiliation: Gerald Reaven is with the Stanford University School of Medicine, Stanford, Calif. 